AMENEDO COSTA, Mónica (2016): "Imagen de Ferrol como espacio plural en fuentes documentales británicas del siglo XVIII". Ángulo Recto. Revista de estudios sobre la ciudad como espacio plural, vol. 8, núm. 1-2, pp. 95-111. ISSN: 19894015.

http://dx.doi.org/10.5209/rev_ANRE.2016.v8.n1.53350

\title{
Imagen de Ferrol como espacio plural en fuentes documentales británicas del siglo XVIII
}

\author{
Mónica Amenedo Costa \\ Departamento de Filoloxía Inglesa \\ Universidade da Coruña \\ mamenedo@udc.es
}

Recibido: $15 / 09 / 2015$

Modificado: 07/07/2016

Aceptado: $30 / 07 / 2016$

\section{Resumen}

En este trabajo se dan a conocer algunas representaciones escritas que la prensa y los documentos de Estado británicos dejaron reflejados en sus páginas sobre Ferrol. Estas fuentes constituyen una prueba de que la ciudad se convirtió en un espacio plural dentro de la sociedad española de mediados del siglo XVIII. En aquella época, el proyecto de reforma naval impulsado por el gobierno de la monarquía borbónica con el fin de salvaguardar los intereses del reino jugó un papel determinante en la configuración socioeconómica de la ciudad, a la que llegaron ciudadanos de diversas procedencias y áreas de actividad. A raíz de albergar un importante puerto militar, la imagen que se proyectó de la ciudad al exterior estuvo ampliamente relacionada con actividades navales y operaciones portuarias que le conferían un carácter dinámico.

Palabras clave: ciudad, Ferrol, documentación británica, siglo XVIII.

Title: Ferrol as a Plural Space: Analysis of Eighteenth-century British Documentary Sources

\section{Abstract}

In this work special emphasis is given to written representations of the city of Ferrol which were included in the British press and State papers. Such an approach will provide evidence for understanding the dynamic character of Ferrol by the middle of the eighteenth-century. At that time, the project of naval reform, which was initiated by the government of the Bourbon monarchy in order to safeguard the interests of the kingdom, played a key role in shaping the socioeconomic characteristics of this town, which had a mixture of migrated people from different backgrounds and professions. Due to the fact that it was a strategically important military port, the image projected of Ferrol abroad was closely linked to its naval activities and port operations which were indicative of its dynamic environment.

Keywords: town, Ferrol, British documents, eighteenth century. 
AMENEDO COSTA, Mónica (2016): "Imagen de Ferrol como espacio plural en fuentes documentales británicas del siglo XVIII". Ángulo Recto. Revista de estudios sobre la ciudad como espacio plural, vol. 8, núm. 1-2, pp. 95-111. ISSN: 19894015.

http://dx.doi.org/10.5209/rev_ANRE.2016.v8.n1.53350

La prensa británica del siglo XVIII dedicó amplios espacios a cuestiones vinculadas con los avatares políticos de la época. Un lugar preferente en estas fuentes documentales lo ocuparon las relaciones internacionales que abrieron la puerta a la inclusión de noticias de carácter político, económico y social relacionadas con el exterior (Harris 1993: 8). La publicación de este tipo de informaciones era relevante para una ciudadanía que estaba pendiente de los asuntos que acontecían en el extranjero e interesada en conocer el devenir político de otros estados (Black 2001: 78). Estos temas también fueron objeto de atención por parte de agentes del cuerpo diplomático y consular así como de personal de diversos organismos británicos. La correspondencia mantenida entre diferentes oficinas del Estado en relación a cuestiones de gobierno ofrece un claro ejemplo de la circulación de información de unos lugares a otros, así como de la comunicación como proceso de interacción y diálogo. A través de las noticias publicadas en las cabeceras de prensa y de los contenidos incluidos en los documentos gubernativos se obtiene una visión directa de lo que fueron reflejos de la vida en ciudades europeas y españolas que tuvieron protagonismo y proyección exterior, como fue el caso de Ferrol. Las noticias extranjeras que se hacían circular tanto desde despachos privados como desde la prensa giraban en torno a acontecimientos que tenían lugar en localidades que habían ido cobrando relevancia como actores en el mapa geopolítico del momento. Esta cobertura informativa favoreció el tratamiento de temas sobre Ferrol, que quedó reflejada en la prensa escrita junto con otras ciudades como Ámsterdam, Berlín, Bruselas, Dublín, La Haya, Lisboa, Madrid, Roma o Viena.

Las fuentes oficiales y de prensa se han estudiado con el fin de avanzar en el conocimiento de cuál era la percepción de la imagen de Ferrol en Gran Bretaña a mediados del siglo XVIII, cuando los planes y proyectos emprendidos en el ámbito naval durante los gobiernos de los monarcas Felipe V (1683-1746) y Fernando VI (1713-1759) habían condicionado de forma notable las funciones y estructura de la ciudad. La reflexión se sitúa en evaluar el tipo de noticias que se difundían en los documentos en tanto que la transmisión y recepción de mensajes, ideas y saberes dentro del contexto cultural de aquella época representa un camino hacia una mayor aproximación histórica de la realidad social, no solo desde un marco geográfico internacional sino también local.

La representación de la sociedad ferrolana en la actividad periodística y política británica constituye un recordatorio histórico en 
AMENEDO COSTA, Mónica (2016): "Imagen de Ferrol como espacio plural en fuentes documentales británicas del siglo XVIII". Ángulo Recto. Revista de estudios sobre la ciudad como espacio plural, vol. 8, núm. 1-2, pp. 95-111. ISSN: 19894015.

http://dx.doi.org/10.5209/rev_ANRE.2016.v8.n1.53350

el que se da cabida a ecos y acontecimientos de la vida diaria de la ciudad. La creación de las instalaciones militares fue un condicionante decisivo para su desarrollo socioeconómico y para su posicionamiento a nivel internacional. La imagen que se construía de Ferrol se presentaba en términos de crecimiento económico y demográfico y de generación de puestos de trabajo en torno al ámbito naval. Esta impronta quedó perpetuada en su expansión física y claramente expresada en la huella dejada a su paso por la presencia de gentes venidas de otras partes de la Península y del extranjero. Su fama de gran arsenal marítimo empezaba ya a quedar grabada en los escritos oficiales que circulaban entre diversos organismos del Estado a mediados de siglo. En 1751, John Harris, un trabajador británico que había estado empleado en la construcción de navíos en Ferrol, describía a las autoridades de su país los trabajos que se estaban efectuando en el espacio portuario del siguiente modo:

[...] at that Port great Improvements are made \& still carrying on in enlarging the yard, and in all manner of Conveniencys for building and fitting out Ships of War, the Building place is about two miles from Ferrol, called Monto Stiro, a place well adapted for such a design, there is about 10 feet flow, and sufficient Depth of water for large ships to lay very near the shore, altho' the Tide does not Ebb low enough to make a Dock yet is sufficient for digging proper slips for building \& laying the Slideing Planks for Launching, [...], and is likely to become a grand magazine [...]. (TNA SP 42/35: 48) ${ }^{1}$

En los documentos hemerográficos también se reconocían las grandes obras que se estaban realizando en el puerto con el fin de contar con una poderosa industria naval. En ellos se señalaba que, cuando estuvieran finalizadas, constituirían el trabajo más grande en Europa de esta índole ${ }^{2}$. La imagen de este activo centro industrial así como las características de la ría se iban convirtiendo en una información recurrente que ayudaba a capturar su esencia y sus ventajas, que también eran conocidas por el gobierno español. En la década de los cuarenta, esta circunstancia se había puesto de

1 Carta fechada el dos de mayo de 1751 y remitida desde las oficinas del Almirantazgo a la Secretaría de Estado del Departamento del Sur para trasladar al duque de Bedford (1710-1771), responsable por aquel entonces de ese organismo gubernamental, las informaciones aportadas por Harris.

2 Noticias publicadas en el mes de enero de 1754 en Read's Weekly Journal or British Gazetteer, 8486 y The Whitehall Evening Post, 1239. Procedían de un fragmento de una carta de Ferrol fechada el 20 de noviembre del año anterior. 
AMENEDO COSTA, Mónica (2016): "Imagen de Ferrol como espacio plural en fuentes documentales británicas del siglo XVIII". Ángulo Recto. Revista de estudios sobre la ciudad como espacio plural, vol. 8, núm. 1-2, pp. 95-111. ISSN: 19894015.

http://dx.doi.org/10.5209/rev_ANRE.2016.v8.n1.53350

manifiesto en la decisión de trasladar la construcción naval de los antiguos establecimientos militares situados en A Graña al denominado monte Esteiro. Algunos de sus elementos y funciones se detallaban como se cita a continuación:

The Harbour is very extensive, being thirty Miles in Circumference, and its Entrance so narrow that a Cable will reach from one Side to the other, and is strongly fortified. [...] but the greatest Work is their inclosing part of this Harbour into a Bason to lay the Ships up in, with a Mould, or Quay, which Foundation is laid in five Fathom of Water, above a Mile in length and 40 Yards broad; upon this Quay, on the Inside, are Storehouses; on the Outside a Line of Defence, that will mount a great Number of Cannon, and when completed will be the greatest Work of the Kind in Europe; 12000 Men are employ'd on these Works; [...]. (Read's Weekly Journal or British Gazetteer 8486; The Whitehall Evening Post 1239)

Los documentos emanados de la Secretaría de Estado del Departamento del Sur y de diversos organismos dependientes de ella son una muestra de que el gobierno británico centró su atención en la obtención de noticias sobre Ferrol. La redacción de informes de inteligencia sobre lo que acontecía en la ciudad era de especial relevancia para Gran Bretaña en tanto que la localidad en aquella época comenzaba a desempeñar un destacado papel en el ámbito naval. Desde allí se ponían en marcha actividades y operaciones portuarias que podían tener repercusiones en su economía y, por tanto, podían afectar a sus intereses y determinar su gestión política. La recepción y transmisión de correspondencia fueron algunos de los quehaceres cotidianos de los cargos políticos y diplomáticos dado que la disponibilidad de información de lo que acontecía en el extranjero constituía uno de los pilares en el ámbito de la política exterior.

Los responsables de esta Secretaría de Estado mantenían contactos periódicos con los servicios de inteligencia que estaban distribuidos entre los estados dentro de su competencia, tal y como fue el caso de España, Francia y Portugal, puesto que en el ejercicio de las funciones de este organismo se abordaba el tratamiento de asuntos relativos al sur de Europa (Browning 1975: 44-45). Habitualmente, las informaciones eran trasladadas por el personal diplomático que se encontraba residiendo en Madrid, París y Lisboa, y por agentes dentro de la red consular desde ciudades como A Coruña, Cádiz, Cartagena y Oporto. El cónsul en A Coruña disponía de informantes y agentes secretos en Ferrol que trataban de recabar datos puntuales acerca de la crónica política, naval y social de la 
AMENEDO COSTA, Mónica (2016): "Imagen de Ferrol como espacio plural en fuentes documentales británicas del siglo XVIII". Ángulo Recto. Revista de estudios sobre la ciudad como espacio plural, vol. 8, núm. 1-2, pp. 95-111. ISSN: 19894015.

http://dx.doi.org/10.5209/rev_ANRE.2016.v8.n1.53350

ciudad. La recepción de estos informes periódicos de ocurrencia de eventos conllevaba una serie de costes que asumía el propio gobierno de Londres (TNA SP 94/224: s.p.; TNA SP 89/41: 82). Esta evidencia documental certifica, por una parte, el carácter marcadamente político de la información que se difundía entre el personal de diversas instituciones, y por otra, el valor de la exactitud y autenticidad de los contenidos.

La prensa también se preocupaba de obtener y difundir noticias provenientes del extranjero, especialmente en un tiempo en que existía una restricción legal para la publicación de temas de política interior que causaba una escasez de contenidos de índole parlamentaria (Hanson 1967: 33). Estas limitaciones, junto con el interés de la ciudadanía por mantenerse informada sobre asuntos relativos a planes y programas de otros gobiernos, fomentaron la inclusión de contenidos del exterior (Black 2001: 44). Ferrol, como sede de un destacado complejo naval, resultó ser un referente internacional donde tenían lugar acontecimientos ampliamente demandados por los lectores y que podían ser pertinentes para la situación económica y social británica, especialmente en un tiempo en que su Marina garantizaba en gran medida el poder nacional y la prosperidad comercial (Wilson 1994: 132). Las noticias sobre la ciudad abordaban asuntos de trascendencia que las publicaciones periódicas supieron acoger para satisfacer las necesidades informativas de la población. Los editores se esforzaban en seleccionar los datos que parecían más exactos y en explicar el fundamento de aquellos más improbables (Black 1986: 67). Las informaciones se iban ampliando y actualizando, lo que permitía proporcionar una imagen más aproximada de la realidad y un conocimiento más objetivo sobre la misma.

Las diversas formas de describir Ferrol dan cuenta de una ciudad plural en continuo movimiento. A ella no solo se trasladaban los confidentes del gobierno británico que se encargaban de emitir informes de inteligencia para el servicio de su majestad sino también batallones de los regimientos de la monarquía borbónica. Las fortificaciones de la ría y las necesidades de defensa del puerto militar requerían su presencia. Tal fue el caso del regimiento de Toledo que, en 1739, guarnecía los castillos y baterías de costa así como de otros destacamentos militares, compuestos por hombres de 
AMENEDO COSTA, Mónica (2016): "Imagen de Ferrol como espacio plural en fuentes documentales británicas del siglo XVIII". Ángulo Recto. Revista de estudios sobre la ciudad como espacio plural, vol. 8, núm. 1-2, pp. 95-111. ISSN: 19894015.

http://dx.doi.org/10.5209/rev_ANRE.2016.v8.n1.53350

los regimientos de Irlanda, Lisboa y Navarra (TNA SP 94/224: s.p.) ${ }^{3}$. Informaciones publicadas en la prensa informaban que el gobierno de la monarquía había resuelto cerrar la boca de la ría de Ferrol con una cadena ante el temor de un ataque británico (The Daily Gazetteer 1283, 1 de agosto de 1739). La creación de esta cadena, que sería colocada de un extremo a otro de la entrada de la ría con el fin de impedir el acceso a los navíos extranjeros, había provocado la concentración en Ferrol de las fuerzas reales, compuestas por unos veinte mil hombres que trabajaban con gran diligencia en su colocación (The Daily Gazetteer 1304, 25 de agosto de 1739; The Scots Magazine, agosto de 1739). El general de división irlandés Macdonald estaba al mando de los regimientos acampados allí (The Daily Gazetteer 1283, agosto de 1739) y mantenía informado del estado de ejecución de las obras al Conde de Itre, Capitán General de Galicia (TNA SP 94/133: s.p.).

Por aquellas fechas, el cónsul John Burnaby Parker en A Coruña manifestaba que todas estas disposiciones habían sido ocasionadas por las noticias recibidas en la corte -que habían sido trasladadas a Ferrol en el mes de julio- de un probable ataque británico a la localidad, lo cual corroboraba las informaciones difundidas en la prensa. El clima de tensión que se instaló en las relaciones angloespañolas se trasladó a la población ferrolana. El riesgo de entrar en guerra se había hecho sentir en las órdenes que habían sido remitidas al intendente y al comandante de Marina con el fin de suspender el desarme de unos navíos que habían llegado de Cádiz y de armar algunos más que ya hacía un tiempo que se encontraban en el puerto (TNA SP 94/224: s.p.) ${ }^{4}$. Esta preocupación se puso de manifiesto también en otras ciudades españolas como Alicante. El clima de tensión política y social llevó a que los ciudadanos ingleses residentes en aquella localidad tomaran la decisión de trasladarse con todas sus pertenencias a su país de origen (The Daily Gazetteer 1293, 13 de agosto de 1739).

La entrada en la Guerra de la Oreja de Jenkins contra Gran Bretaña derivó en una intensa actividad de carácter político-militar en Ferrol. En la correspondencia oficial se transmitían datos puntuales sobre los planes y objetivos del gobierno que eran de interés general

${ }^{3}$ Carta del cónsul John Burnaby Parker en A Coruña al Secretario de Estado para el Departamento del Sur, Thomas Pelham-Holles, Duque de Newcastle (1693-1768), fechada el 10 de julio de 1739.

${ }^{4}$ Carta enviada por Parker al Duque de Newcastle, con fecha de 4 de junio de 1739. 
AMENEDO COSTA, Mónica (2016): "Imagen de Ferrol como espacio plural en fuentes documentales británicas del siglo XVIII". Ángulo Recto. Revista de estudios sobre la ciudad como espacio plural, vol. 8, núm. 1-2, pp. 95-111. ISSN: 19894015.

http://dx.doi.org/10.5209/rev_ANRE.2016.v8.n1.53350

para las autoridades en Londres. Las operaciones navales que se efectuaban por aquel entonces motivaron la presencia de un buen número de navíos en la localidad. El embajador en Francia, James Waldegrave (1684-1741), anunciaba la llegada de la escuadra de Cádiz a la urbe ferrolana (TNA SP 78/223: 5) ${ }^{5}$. También el cónsul Parker, que ahora informaba desde Oporto a donde se había trasladado a causa de la ruptura de las relaciones anglo-españolas, facilitaba información de varias fragatas y navíos de guerra procedentes de Cádiz y de la presencia de una escuadra compuesta por nueve barcos de guerra, lo que hacía un total de dieciocho navíos de guerra y tres fragatas ${ }^{6}$. Estas descripciones de los movimientos portuarios también se ofrecían en la prensa (The Daily Gazetteer 1535, 21 de mayo de 1740) y son reflejo de una sociedad llena de energía y en continuo movimiento.

Desde esta perspectiva, las instalaciones militares se constituyeron como el eje de la vida en el mundo urbano ferrolano y el puerto en un espacio que contribuye a la entrada de personas provenientes de otros lugares. A través del mar se tiene contacto con otros territorios y se abren las puertas a nuevas experiencias en la ciudad. Además de las tripulaciones que formaban parte de los navíos que se encontraban fondeados en el puerto, otros fueron los individuos que llegaron a Ferrol por mar. Véase el caso de los prisioneros que habían sido capturados durante la guerra debido al apresamiento de navíos ingleses, algunos de los cuales fueron trasladados a Ferrol (The Scots Magazine 2, mayo de 1740; The Gentleman's Magazine 11, diciembre de 1741). Las condiciones de vida de estos hombres eran muy duras y no contaban con ninguna retribución que les permitiera salir de la situación de hambruna que padecían (TNA SP 89/41: 30). Ante tales circunstancias, algunos optaron por alistarse o bien en el ejército español o bien en los barcos de guerra que había en la ciudad. Estas decisiones suponían

\footnotetext{
${ }^{5}$ Carta de Waldegrave al Duque de Newcastle, enviada desde París con fecha de 16 de mayo de 1740. El embajador había obtenido estas informaciones, por un lado, a través de cartas procedentes de Cádiz, que comunicaban la salida de la escuadra de Cádiz hacia Ferrol. Por otro, en una conversación mantenida con un caballero irlandés, apellidado Baguel. En su viaje hacia Inglaterra, Baguel se había detenido doce días en Bayona donde se hablaba confidencialmente de la presencia de la escuadra de Cádiz en Ferrol. Baguel estaba casado con la viuda de Higgins, que había sido médico del monarca español Felipe $V$.

6 John Burnaby Parker al Duque de Newcastle. Oporto, 27 de abril de 1740 (TNA SP 89/41: 28).
} 
AMENEDO COSTA, Mónica (2016): "Imagen de Ferrol como espacio plural en fuentes documentales británicas del siglo XVIII". Ángulo Recto. Revista de estudios sobre la ciudad como espacio plural, vol. 8, núm. 1-2, pp. 95-111. ISSN: 19894015.

http://dx.doi.org/10.5209/rev_ANRE.2016.v8.n1.53350

una mejora en su calidad de vida y unas relaciones con personas con pautas culturales distintas, lo cual fomentaba la aparición de subculturas en el ámbito del trabajo. De acuerdo con Solano de las Aguas (2010: 421-422),

[m] uchos elementos de las subculturas laborales de marineros y gentes de todas las procedencias eran asimilados y resignificados por los sectores populares. Canciones de trabajo, vocabulario técnico, jergas, santos patronos, proverbios y adagios, souvenires, conocimientos astronómicos y meteorológicos, formas de ingerir licor, experiencias sexuales de otras latitudes, rituales como el bautismo de las embarcaciones y del novel navegante, leyendas mitológicas, historias, chistes, supersticiones y magias para conjurar el peligro, juegos de azar, etc., de estas subculturas llegaron a formar parte del corpus cultural popular.

Las autoridades británicas intentaron dar solución a la situación a la que se veían enfrentados sus súbditos mediante el establecimiento de acuerdos con el gobierno de la monarquía borbónica. En Londres se consideró oportuno efectuar un intercambio de prisioneros y evitar, de ese modo, que sus ciudadanos se pusieran al servicio del enemigo (TNA SP 89/41: 115) ${ }^{7}$. En julio de 1742, las negociaciones dieron sus frutos con la suscripción de un acuerdo en el que ambas partes se comprometían a dar los pasos necesarios para la liberación de estos hombres (TNA SP 89/43: 118).

La creación del astillero y del arsenal determinó la vida en Ferrol y su configuración social, que giraba en torno a las instalaciones portuarias y fortalezas militares creadas con el propósito de formar una Marina poderosa y respetable. Estos nuevos espacios estimularon la presencia de diversos actores sociales en el mundo urbano, los cuales quedaron organizados a partir de las nuevas actividades laborales que se desarrollaban. Entre ellos cabe hacer referencia al personal militar y a los trabajadores de la maestranza, entre los que se encontraban los constructores, ayudantes de construcción, herreros, carpinteros, calafates y aserradores. Asimismo, también cabe hacer mención a otros grupos muy diversos que aglutinaban a artesanos, tenderos, sastres, taberneros y prostitutas (Vigo Trasancos 1984: 130).

\footnotetext{
7 Sobre el asunto de estos prisioneros, véase el trabajo de Amenedo Costa titulado "La guerra, el corso marítimo y sus repercusiones" (2009).
} 
AMENEDO COSTA, Mónica (2016): "Imagen de Ferrol como espacio plural en fuentes documentales británicas del siglo XVIII". Ángulo Recto. Revista de estudios sobre la ciudad como espacio plural, vol. 8, núm. 1-2, pp. 95-111. ISSN: 19894015.

http://dx.doi.org/10.5209/rev_ANRE.2016.v8.n1.53350

Esta fase de desarrollo económico se configuraba en torno a nuevas identidades urbanas muy diferentes entre sí. Por aquel tiempo la ciudad se convertía en un espacio de vida para todos los sectores sociales que participaban, de una u otra manera, en el proceso de cambio social. Tal y como establece Martín García (2002: 431), la creación "de un complejo-bélico industrial de las dimensiones del ferrolano suponía la necesidad de una numerosa mano de obra que no podía satisfacerse con la única aportación de los vecinos de la comarca". Los documentos gubernativos también ponen de manifiesto la presencia de colectivos marginados que se precisaban para la realización de las tareas más arduas en las impresionantes obras que se habían emprendido en la ciudad. En 1752, la Secretaría de Estado del Departamento del Sur recibía noticias de la llegada a Ferrol, en los navíos Dragón y América, de ciento cincuenta personas de procedencia musulmana que se habían empleado, junto con los gitanos y otro tipo de esclavos, en esta clase de trabajos (TNA SP 94/227: s.p. $)^{8}$. Las duras condiciones laborales y de vida a las que estaba sometida esta mano de obra forzada, cuya llegada a Ferrol no se había realizado de manera voluntaria, la hacían especialmente vulnerable ${ }^{9}$. Desde A Coruña, el cónsul Joseph Jordan indicaba que había una elevadísima tasa de mortalidad entre estos pobres desgraciados, falleciendo diariamente entre cuatro y ocho personas y que se enterraban juntas a unas cinco o seis, lo cual le hacía temer que en cualquier momento pudiera desencadenarse una seria epidemia de peste, especialmente ante la próxima llegada del tiempo caluroso (TNA SP 94/227: s.p.).

En aquel agitado periodo de mediados de siglo, el gobierno de la monarquía también empleaba como mano de obra barata a militares alistados en los regimientos extranjeros de Bruselas, Flandes, Hibernia, Irlanda y Ultonia, que formaban parte del ejército borbónico (Abad León 1985: 313; Ozanam 1980: 110). Esta configuración del ejército propiciaba la presencia de personas de diferentes procedencias en la ciudad, tales como italiana, francesa, suiza o irlandesa. Unos dos mil quinientos soldados realizaron tareas bastante tediosas llegando "incluso a suplir la deficiencia de

${ }^{8}$ Carta de Joseph Jordan al Secretario de Estado Holdernesse, remitida en abril de 1752.

9 En enero de aquel año, un contingente de hombres compuesto por quinientos cuarenta y tres gitanos, ciento treinta y nueve vagos y dos desterrados había sido trasladado desde Cádiz a Ferrol donde desempeñaban tareas muy arduas y penosas (Martín García 1999: 251). 
AMENEDO COSTA, Mónica (2016): "Imagen de Ferrol como espacio plural en fuentes documentales británicas del siglo XVIII". Ángulo Recto. Revista de estudios sobre la ciudad como espacio plural, vol. 8, núm. 1-2, pp. 95-111. ISSN: 19894015.

http://dx.doi.org/10.5209/rev_ANRE.2016.v8.n1.53350

presidiarios en trabajos tan agotadores como los de las bombas de cadenas en los diques" (Martín García 1999: 236).

Con la creación del nuevo centro naval se sentaron las bases para la transformación social de la ciudad, que albergó gran cantidad de trabajadores durante el tiempo en que se llevaron a cabo los trabajos. A comienzos de 1754 , las fuentes de prensa británicas cifraban el número en doce mil (Read's Weekly Journal or British Gazetteer 8486; Whitehall Evening Post 1239) en una localidad "que en 1749 sólo contaba con doscientos cincuenta vecinos [...]" (Montero y Aróstegui 1972: 46). Estos datos anuncian el significativo incremento demográfico que experimentó Ferrol en aquellas fechas. El arsenal y el consecuente crecimiento de la población tuvieron una incidencia en las actividades económicas y en el tráfico marítimo. Al puerto ferrolano llegaban embarcaciones que depositaban materiales para la construcción naval, entre las que cabe destacar la madera o el carbón (TNA SP 94/227, s.p.), así como productos de primera necesidad para satisfacer las demandas de los residentes, como carne, trigo y vino. En el ámbito del comercio interior, la distribución de mercancías se realizaba desde ciudades como Bilbao, Gijón y Santander. Del exterior se importaban productos de Riga, Dublín, Bristol o Newcastle (Meijide Pardo 1960: 444; Labrada 1971: 32). Estas operaciones portuarias posibilitaban el establecimiento de relaciones comerciales y culturales con personas provenientes de diversas partes del mundo.

El extraordinario crecimiento de la ciudad repercutió en su expansión física. En efecto, "[a]l propio tiempo que con tan asombrosa rapidez se echaban los cimientos del mejor arsenal marítimo que en aquellos tiempos fue conocido en el mundo, se levantaba a su lado la nueva población del Ferrol" (Montero y Aróstegui 1972: 45). En un primer momento se realizó la edificación de la población de Esteiro, que fue coincidente con las obras de construcción de las gradas del astillero. En este barrio residían los miembros de la clase obrera, principalmente el proletariado industrial. Contaba con dos plazas y estaba formado por seis calles longitudinales, de cuatrocientos veintiocho metros de extensión, que se presentaban cortadas por travesías (Montero y Aróstegui 1972: 224). La construcción de la población de la Magdalena fue contemporánea a la del arsenal. En ella participaron destacados ingenieros del periodo como Joseph Petit de La Croix, Francisco Llobet y Julián Sánchez Bort. En esta población se alojaban grupos sociales económicamente más favorecidos que los que residían en Esteiro (Clemente Cubillas 1984: 49). Sus calles estaban rigurosamente 
AMENEDO COSTA, Mónica (2016): "Imagen de Ferrol como espacio plural en fuentes documentales británicas del siglo XVIII". Ángulo Recto. Revista de estudios sobre la ciudad como espacio plural, vol. 8, núm. 1-2, pp. 95-111. ISSN: 19894015.

http://dx.doi.org/10.5209/rev_ANRE.2016.v8.n1.53350

alineadas y sus manzanas eran "cuadrilongas, pero enteramente iguales" (Montero y Aróstegui 1972: 226). El barrio disponía de dos grandes plazas, la de Dolores y la de Armas o del Carmen, en las que desembocaban varias calles y traviesas. Con respecto a su tipología arquitectónica, y sin olvidar el papel estético en el que se buscaba la uniformidad que se consigue con las galerías ornamentales situadas en las fachadas, cabe hacer referencia a su carácter funcional, dado que se programaron "pasos peatonales cubiertos por soportales, con arcos de medio punto y elevados mediante cuatro escalones sobre el nivel de la calle" (Clemente Cubillas 1984: 47-48).

En el barrio de la Magdalena se desempeñaba una importante actividad comercial. Los habitantes de la nueva urbe desarrollaban su vida cotidiana en los recién construidos espacios urbanos, siendo de destacar algunas de las actividades que se acogían en sus plazas. La de Dolores, en la que se encontraba la capilla de esta Virgen, había adquirido importancia en la venta de productos de primera necesidad. Por su parte, en la de Armas también se celebraba un pequeño mercado a primera hora de la mañana aunque, según establece Montero y Aróstegui (1972: 228), su principal actividad era la de la leña, "concurriendo a ella los miércoles y sábados inmensidad de carros del país cargados de aquel combustible".

Ferrol era una ciudad razonablemente dinámica con una destacada proyección en el exterior. En ella se podían apreciar variadas expresiones y manifestaciones culturales debido a la diversidad de sus habitantes. Sus calles se habían convertido en un hervidero de personas de diferentes procedencias, con lenguas, valores, costumbres y tradiciones diversas. Las expectativas profesionales que se crearon en torno a la nueva industria naval habían motivado el traslado de numerosas personas de dentro de la Península así como del extranjero, lo que se reconoce históricamente como una fuente de diversidad cultural. La presencia de un grupo inmigrante compuesto por ciudadanos de origen británico e irlandés constituye un nuevo ejemplo de la pluralidad existente en la localidad. Este colectivo se había asentado en Ferrol a consecuencia de los planes de reforma naval que el gobierno de la monarquía había decidido poner en marcha en aquella centuria. La falta de técnicos y especialistas en el ámbito de la construcción naval había motivado la contratación de trabajadores en Gran Bretaña.

El Marqués de la Ensenada (1707-1781), en el ejercicio de sus funciones en diversos ministerios durante el reinado de Fernando VI (1746-1759), se preocupó de adoptar importantes medidas en el ámbito de la Marina con el fin de proteger y defender los intereses del 
AMENEDO COSTA, Mónica (2016): "Imagen de Ferrol como espacio plural en fuentes documentales británicas del siglo XVIII". Ángulo Recto. Revista de estudios sobre la ciudad como espacio plural, vol. 8, núm. 1-2, pp. 95-111. ISSN: 19894015.

http://dx.doi.org/10.5209/rev_ANRE.2016.v8.n1.53350

reino. Algunas de ellas se enfocaron en la necesidad de importar técnicos dado que España carecía de ellos (Fernández Duro 1973: 377), así como de mejorar los métodos de construcción naval que se habían estado siguiendo hasta la fecha y de "cambiarlos por los que aplicaban los ingleses" (Lozano et al. 1997: 24). La transferencia de conocimiento se realizó a través de la contratación de especialistas y operarios que trabajaban en las instalaciones navales británicas, muchos de los cuales se asentaron en Ferrol junto a sus familias ${ }^{10}$. Con su trabajo, los nuevos vecinos contribuyeron al avance marítimo y favorecieron la introducción de conocimiento en los diversos gremios en los que se hallaban divididos.

En los documentos que circulaban entre la Secretaría de Estado del Departamento del Sur y otros organismos oficiales, así como en las noticias que se publicaban en la prensa periódica, se daba cobertura a la pérdida de esta mano de obra de sus instalaciones y al progreso naval propiciado por el gobierno borbónico en el que tenían una relevancia singular los ciudadanos de su país. Especial mención recibían el constructor Ricardo Rooth y otros hombres como Guillermo Clark y Tomás Hewett (TNA SP 42/35: 48-49; TNA SP 94/227: s.p.; TNA P94/228: s.p.). La renovación del sistema de construcción de navíos quedaba constatada en la buena marcha de las actividades que se desenvolvían en el centro naval, donde se llegaron a tener hasta doce quillas en diversas gradas. La evolución de las botaduras de los navíos, que se realizaban siguiendo el modelo inglés, era prueba de que el programa naval de Ensenada no era una vaga aspiración. En 1754, publicaciones como The Whitehall Evening Post y The New Universal Magazine ponían en conocimiento de sus lectores el destacado fortalecimiento marítimo español que estaba siendo favorecido por sus compatriotas. The New Universal Magazine (14.93, enero de 1754) lo publicaba en los siguientes términos:

\footnotetext{
10 Sobre el estudio de este colectivo inmigrante, véase el trabajo de Amenedo Costa titulado La población británica e irlandesa en el Ferrol de la Ilustración. Análisis de fuentes demográficas gallegas y documentación de estado británica (2012).
} 
AMENEDO COSTA, Mónica (2016): "Imagen de Ferrol como espacio plural en fuentes documentales británicas del siglo XVIII". Ángulo Recto. Revista de estudios sobre la ciudad como espacio plural, vol. 8, núm. 1-2, pp. 95-111. ISSN: 19894015.

http://dx.doi.org/10.5209/rev_ANRE.2016.v8.n1.53350

Letters from Spain advise, that there have been lately launched at Ferrol four ships of sixty four guns, which are as large as the English ships of eighty or ninety guns, for they have 150 feet keel, and fifty feet extreme breadth. Twelve others of the same dimensions are on the stocks. The ship-builders are all English.

Estos ciudadanos inmigrantes y sus familias fomentaron la interculturalidad en Ferrol. Muchos de ellos residieron en la localidad hasta el final de sus días. Su integración se hizo notar en sus aportaciones y trabajos de manera conjunta con sus compañeros en el arsenal, así como en los vínculos que crearon con otros vecinos dentro del espacio urbano. Al tiempo que estaban unidos con gentes de su mismo origen por lazos de amistad y de parentesco, también mantuvieron vínculos con personas fuera de su grupo inmigrante. Véase el caso de aquellos ciudadanos nativos que participaron como padrinos en algunas de las celebraciones religiosas de esta comunidad extranjera o el de aquellos individuos extranjeros que desempeñaron la misma función en bautismos de niños de familias españolas ${ }^{11}$. Estas relaciones sociales aportaron claros beneficios a la sociedad receptora y supusieron una vía de inmersión de la población inmigrante en la vida de Ferrol.

Sin embargo, la homogeneidad cultural presente en aquel periodo de la Edad Moderna resultó ser un condicionante para acoger en su seno algunas de las costumbres que tenían las personas llegadas de Gran Bretaña, tal y como se pone de manifiesto en la falta de libertad que experimentaron algunas de ellas para practicar sus creencias. Los ciudadanos que no eran católicos tenían la obligación de profesar esta religión con el fin de no diluir la cultura mayoritaria de la sociedad en este ámbito. Este hecho impidió la integración de John Harris, que optó por escapar y marchar a su país de origen (TNA SP 42/35: 48-49), pero sirvió como vía a través de la cual inmigrantes como Thomas Williams mostraron su deseo de integración en las tradiciones de su nueva localidad de destino (ADM P. de San Julián de Ferrol, L. 5 de def.: 276). La presión religiosa continuó existiendo a lo largo del siglo. A mediados de la nueva

${ }^{11}$ Estos datos han quedado reflejados en libros parroquiales que se custodian en el Archivo Diocesano de Mondoñedo (ADM). A modo de ejemplo, véanse los libros de bautismos cuatro, cinco y seis correspondientes a la parroquia de San Julián (ADM P. de San Julián, L. 4 de baut.: 59; ADM P. de San Julián: 46; ADM P. de San Julián, L. 6 de baut.: 15, 96, 292, 339). 
AMENEDO COSTA, Mónica (2016): "Imagen de Ferrol como espacio plural en fuentes documentales británicas del siglo XVIII". Ángulo Recto. Revista de estudios sobre la ciudad como espacio plural, vol. 8, núm. 1-2, pp. 95-111. ISSN: 19894015.

http://dx.doi.org/10.5209/rev_ANRE.2016.v8.n1.53350

centuria, la ciudad volvió a ser testigo de la conversión de extranjeros al catolicismo, a raíz de una nueva llegada de familias inglesas a la localidad. Montero y Aróstegui (1972: 147) indica que estas ceremonias eran un espectáculo poco común al que "concurría gran número de personas a presenciar los primeros bautismos que se celebraron".

La imagen de Ferrol como un lugar plural de encuentro de manifestaciones culturales diversas ha quedado reflejada en las fuentes documentales británicas que se han analizado en este trabajo. Sobre esta base, se puede argumentar que tanto la correspondencia de Estado como las publicaciones periódicas desempeñaron un papel destacado en el acercamiento de cuestiones políticas y culturales a la realidad cotidiana de sus lectores. La circulación de noticias de actualidad sobre asuntos exteriores derivó en la formación de una ciudadanía consciente de las estrategias, decisiones y proyectos que se llevaban a cabo en ciudades extranjeras. Su lectura ofreció la oportunidad de viajar mentalmente, así como de trasladarse y explorar la vida de otros espacios físicos. Uno de aquellos lugares fue Ferrol, donde la afluencia de personas atraídas por las posibilidades de trabajo que abría la intensa actividad económica generada por la creación del arsenal posibilitó el contacto de gentes de diversos orígenes y el intercambio de conocimientos e ideas. Estas experiencias urbanas dejaron su huella no solo en el sector industrial sino también en el ámbito social, a pesar de que, en ocasiones, la diversidad cultural no fue reconocida como una fuerza positiva dentro de la sociedad.

El arsenal dio lugar a una particular configuración social y urbanística en una ciudad que vio nacer proyectos que son ejemplo de una urbe trazada de manera completamente planificada. Ferrol, como localidad portuaria, tuvo la oportunidad de ver llegar a personas de diferentes orígenes, tanto de dentro de la Península como del exterior, y de entablar vínculos con diversos y distantes territorios. La construcción y defensa de sus fortificaciones, necesarias para dar la adecuada protección a un puerto militar de tal magnitud, habían causado la llegada de regimientos de la monarquía borbónica en los que se encontraban alistados militares de distintas procedencias geográficas europeas. Durante la Guerra de la Oreja de Jenkins, la pluralidad de las gentes se vio incrementada con los prisioneros británicos que habían sido trasladados a la ciudad en las embarcaciones capturadas al enemigo. Asimismo, Ferrol contó entre sus habitantes con los miembros de un destacado colectivo inmigrante de origen británico e irlandés quienes, a causa de 
AMENEDO COSTA, Mónica (2016): "Imagen de Ferrol como espacio plural en fuentes documentales británicas del siglo XVIII". Ángulo Recto. Revista de estudios sobre la ciudad como espacio plural, vol. 8, núm. 1-2, pp. 95-111. ISSN: 19894015.

http://dx.doi.org/10.5209/rev_ANRE.2016.v8.n1.53350

decisiones políticas tomadas por el gobierno de la monarquía, se habían trasladado a la ciudad para introducir sus conocimientos en el sector de la construcción naval. También formaron parte de la población otros colectivos menos favorecidos y más vulnerables que trabajaron en la realización del proyecto de reforma naval así como grupos que estaban compuestos por espías y agentes del gobierno británico, que se acercaban a la ciudad con el propósito de averiguar aquellos aspectos de relevancia de su acontecer cotidiano y de hacerlos llegar a sus autoridades políticas.

\section{Fuentes primarias}

Archivo Diocesano de Mondoñedo (ADM):

Libro de bautismos núm. 4, 5 y 6 .

Libro de defunciones núm. 5.

The National Archives (TNA)

SP 42; SP 78; SP 89; SP 94.

\section{Fuentes hemerográficas}

Read's Weekly Journal; or, British Gazetter (Londres, 1730-1739, 1750-1761).

The Daily Gazetteer (Londres, 1735-1748).

The Gentleman's Magazine (Londres, 1731-1907).

The Scots Magazine (Edimburgo, 1739-1803).

The Whitehall Evening Post (Londres, 1746-1801).

\section{Bibliografía}

ABAD LEÓN, Felipe (1985): El Marqués de la Ensenada, t. I. Madrid: Editorial Naval.

AMENEDO COSTA, Mónica (2009): "La guerra, el corso marítimo y sus repercusiones", en Manuel-Reyes García Hurtado, Domingo L. González Lopo y Enrique Martínez Rodríguez (ed.), El mar en los siglos modernos, vol. II, pp. 67-76. Santiago de Compostela: Xunta de Galicia.

AMENEDO COSTA, Mónica (2012): La población británica e irlandesa en el Ferrol de la Ilustración. Análisis de fuentes demográficas gallegas y documentación de estado británica. Nueva York: Peter Lang.

BLACK, Jeremy (1986): "The British Press and Europe in the Early Eighteenth Century", en M. Harris y A. Lee (eds.), The Press in English Society from the Seventeenth to the Nineteenth Centuries, pp. 64-79. Londres: Associated University Presses. 
AMENEDO COSTA, Mónica (2016): "Imagen de Ferrol como espacio plural en fuentes documentales británicas del siglo XVIII". Ángulo Recto. Revista de estudios sobre la ciudad como espacio plural, vol. 8, núm. 1-2, pp. 95-111. ISSN: 19894015.

http://dx.doi.org/10.5209/rev_ANRE.2016.v8.n1.53350

BLACK, Jeremy (2001): The English Press 1621-1861. Stroud: Sutton Publishing.

BROWNING, Reed (1975): The Duke of Newcastle. New Haven y Londres: Yale University Press.

CLEMENTE CUBILLAS, Enrique (1984): Desarrollo urbano y crisis social en Ferrol. Santiago de Compostela: Colexio Oficial de Arquitectos de Galicia.

FERNÁNDEZ DURO, Cesáreo (1973): La Armada española desde la unión de los reinos de Castilla y de Aragón, t. VI. Madrid: Museo Naval.

HANSON, Laurence (1967): Government and the Press 1695-1763. Oxford: Clarendon Press.

HARRIS, Robert (1993): A Patriot Press. National Politics and the London Press in the 1740s. Oxford: Clarendon Press.

LABRADA, José Lucas (1971): Descripción económica del Reino de Galicia. Vigo: Galaxia.

LOZANO RODRÍGUEZ, Francisco José; GONZÁLEZ SÁNCHEZ, Pedro; y MARTÍNEZ CORTÉS, Antonio José (1997): La Marina y la ría de Ferrol. Ferrol: Club de Prensa.

MARTÍN GARCÍA, Alfredo (1999): "Levas honradas y levas de maleantes: los trabajadores forzosos en un arsenal del Antiguo Régimen". Obradoiro de Historia Moderna, vol. 8, pp. 231-260.

MARTÍN GARCÍA, Alfredo (2002): Población y sociedad del Ferrol y su tierra en el Antiguo Régimen, vol. I [en línea]. En: http://hdl.handle.net/2183/5532 [Consulta: 11/03/2016].

MEIJIDE PARDO, Antonio (1960): "El comercio marítimo de los países del norte con Galicia en la segunda mitad del siglo XVIII". Estudios geográficos, núm. 81, pp. 443-453.

MONTERO Y ARÓSTEGUI, José (1972): Historia y descripción de El Ferrol. 1858 r.p.t. Ferrol: Gersán.

OZANAM, Didier (1980): "Representación del Marqués de la Ensenada a Fernando VI (1751)". Cuadernos de Investigación Histórica, núm. 4, pp. 67-124.

SOLANO DE LAS AGUAS, Sergio Paolo (2010): "Un problema de escala: la configuración social del puerto en las ciudades del Caribe colombiano", en Jorge Enrique Elías Caro y Antonino Vidal Ortega (eds.), Ciudades portuarias en la gran cuenca del Caribe: Visión histórica, pp. 398-441. Barranquilla: Uninorte.

VIGO TRASANCOS, Alfredo (1984): Arquitectura y urbanismo en el Ferrol del siglo XVIII. Santiago de Compostela: Colexio Oficial de Arquitectos de Galicia. 
AMENEDO COSTA, Mónica (2016): "Imagen de Ferrol como espacio plural en fuentes documentales británicas del siglo XVIII". Ángulo Recto. Revista de estudios sobre la ciudad como espacio plural, vol. 8, núm. 1-2, pp. 95-111. ISSN: 19894015.

http://dx.doi.org/10.5209/rev_ANRE.2016.v8.n1.53350

WILSON, Kathleen (1994): "Empire of Virtue: The Imperial Project and Hanoverian Culture c. 1720-1785", en Lawrence Stone (ed.), An Imperial State at War: Britain from 1689 to 1815, pp. 128-164. Londres: Routledge. 